\title{
РИСКИ И ПРИЧИНЫ ПРЕСТУПНОСТИ НЕСОВЕРШЕННОЛЕТНИХ ЖЕНСКОГО ПОЛА
}

\author{
О.Ю. Каплун (http://orcid.org/0000-0002-1150-4269) \\ Дальневосточный государственнылй университет, Владивосток, Россия, \\ e-mail: ilchenko.oyu@dvfu.ru
}

Актуальность исследования подтверждается тем, что в настоящее время преступное поведение женщин приобрело массовый характер. Цель исследования состоит в выявлении значимых факторов риска, устранение которых дает больший превентивный эффект, чем борьба с последствиями - совершенными женщинами преступлениями. Исследовательской проблемой является влияние различных факторов риска на уровень и динамику женской молодежной преступности. Вторичный анализ результатов исследований позволил обнаружить, что некоторые социальные и индивидуальные факторы связаны с повышенным риском совершения противоправных поступков. Научное и практическое значение итогов работы заключается в выявлении влияния факторов риска, к которым отнесли индивидуальный, родительский/ семейный, взаимодействие со сверстниками, влияние школы и сообщества на женскую молодежную преступность.

Ключевые слова: риски, женская преступность, профилактика преступности, факторы преступности несовершеннолетних, латентная преступность, семья и преступность.

\section{RISK AND CAUSES OF GIRLS' DELINQUENCY O.Yu. Kaplun \\ Far Eastern Federal University, Vladivostok, Russia, e-mail: ilchenko.oyu@dvfu.ru}

Crime has always been considered to be a mainly male activity but evidence shows a recent sharp increase in female crime. Over the last decades, women have been increasing their participation in the crime market. Basing on the analysis of international research data, ehe article shows that the influence of various risk factors on the level and dynamics of female youth crime and girls' delinquency. Secondary analysis of researches has identified these antecedents of girls' delinquency: extreme economic deprivation; neighborhood disorganization; certain physiological characteristics; early and persistent behavior problems, other conduct problems, and hyperactivity in childhood and adolescence; poor family management practices; anti-social behavior and unemployment of parents; family conflict; low bonding to family; academic failure; lack of commitment to school; early peer rejection. 
Keywords: risks, female crime, crime prevention, factors of juvenile crime, latent crime, crime and the family.

DOI 10.14258/ssi(2019)3-6271

Несмотря на общественную значимость проблемы женской преступности, можно констатировать недостаточную проработанность данного вопроса. По сравнению с тем, что известно о мужской преступности, мы по-прежнему мало знаем о женской, в частности о ее рисках. В самом деле, небольшое количество исследований ставят целью изучение женского преступного поведения с точки зрения факторов риска, напротив, большая часть знаний о факторах риска ориентирована на мужчин (Farrington, 2007: 123). Причина заключается в том, что, по сравнению с женщинами, мужчины совершают большее количество преступлений, к тому же структура мужской преступности характеризуется более тяжкими преступлениями.

Понятие «риск» многогранно, его принципиальной чертой является сопряженность с такими терминами, как «опасность», «угроза», «неопределенность результата» (Акулич, 2008: 55). Изучение рисков женской преступности может проводиться в нескольких основных направлениях. Во-первых, изучение риска как источника опасности предполагает, на наш взгляд, установление факторов, предопределяющих вероятность вступления несовершеннолетних на преступный путь. Во-вторых, риск получения ущерба, вреда должен включать изучение влияния последствий женской преступности на развитие российского общества. В-третьих, знание рисков женской преступности позволит выделить защитные факторы, препятствующие развитию данного явления. Речь идет о так называемой парадигме «профилактика факторов риска» (Farrington, 2000: 18). Основная цель выделения указанных факторов заключается в стремлении предотвратить совершение преступлений путем принятия адекватных мер и профилактических программ.

В данной работе анализу будет подвержено первое направление - изучение факторов социального риска, способствующих тому, что несовершеннолетние девушки становятся преступницами. В настоящее время преступное поведение женщин приобрело массовый характер. В этой связи следует согласиться с мнением ученых о том, что, прежде чем бороться посредством карательного аппарата с последствиями - совершенными преступлениями, необходимо выявить те значимые факторы риска, устранение которых дало бы больший превентивный эффект, чем изоляция молодых женщин от общества, что в будущем может лишь помешать успешной интеграции в него (Тейван-Трейновский, 2013: 103).

Принятие несовершеннолетними женского пола преступной модели поведения связано с рядом факторов риска, которые, взаимодействуя между собой, способствуют дезадаптации личности. Факторами риска именуются особенности, обстоятельства и разного рода события или приобретенный жизненный опыт, которые прогнозируют высокую вероятность совершения правонарушений (Farrington, 2004: 201). Концепция факторов риска была впервые применена в исследованиях в области здравоохранения, в которых определялись факторы, способные увеличить или уменьшить шансы злоупотребления алкоголем и наркотиками в подростковом 
и юношеском возрасте. В настоящее время к факторам риска относятся биологические, психологические (поведенческие), а также социальные показатели (Тейван-Трейновский, 2013: 106). Эти факторы, как правило, дихотомичны, т.е. могут выступать в качестве рисков либо, напротив, в качестве превентивных мер.

Вторичный анализ результатов исследований позволил обнаружить, что некоторые факторы, например особенности типа семьи и стиля воспитания, взаимодействие со сверстниками и неуспешность в школе, связаны с повышенным риском совершения противоправных поступков. В частности, влияние может оказывать факт распада семьи, наличие конфликта между родителями или родителями и детьми, низкий интеллект, асоциальность и безработица родителей, многодетность семей, их низкий социально-экономический статус, пропуски школы, плохая успеваемость (Hawkins, 1992: 68). Кроме того, некоторые авторы дополняют данный перечень индивидуальными факторами риска (нерациональное использование свободного времени, дисфункция черт личности и изменение ценностной ориентации) и факторами влияния общества (например, высокий уровень преступности, доступность наркотиков, деформированная ценностная система в обществе, ограниченные возможности получения услуг медицинского и психического обеспечения, неадекватно дорогие услуги образования) (Andrews, 2014: 326).

В данной работе, вслед за Л. Бай, Д. Фаррингтоном и М. Уедой, мы рассмотрим следующие основные факторы риска преступности несовершеннолетних: индивидуальный, родительский/семейный, взаимодействие со сверстниками, влияние школы и сообщества (Bui, 2016: 211). Кратко раскроем каждый из факторов.

Первый фактор - индивидуальный — включает раннее антиобщественное поведение, а также такие эмоциональные факторы, как высокая степень активизации поведения и низкий уровень сдерживания, низкий уровень развития познания, низкий интеллект и гиперактивность.

Первый подфактор включает личные характеристики девушек: желание совершать противоправные поступки для получения собственного удовольствия или чтобы произвести шокирующий эффект на окружающих; стремление делать все, что хочется, не обращая внимания на любые возможные последствия.

Другим подфактором является «потеря лица» (респектабельности), что показывает, насколько молодая женщина опасается потерять самоуважение и уважение со стороны близких, если будет известно, что она, например, ворует или незаконно играет на деньги (Bui, 2016: 214).

Следующий подфактор - это присущие девушке свободные (несдерживаемые) убеждения. Данный подфактор включает убеждения о том, будет ли человек обнаружен и наказан либо, напротив, не обнаружен и не наказан полицией после совершения правонарушений и испытает ли чувство стыда и сожаления при этом. Например, в опроснике Л. Бай для характеристики данного подфактора включены такие утверждения: 1) я считаю, что я была бы поймана полицией, если бы я незаконно играла на деньги или украла что-либо из магазина; 2) мне было бы стыдно, если бы я была поймана и наказана за незаконные азартные игры или кражу из магазина (Bui, 2016: 216). 
Еще одним подфактором риска несовершеннолетних женского пола является «социальная желательность». В указанной работе Л. Бай и коллег для характеристики данной группы используются такие предположения: 1) я иногда чувствую себя ущемленной, если мне не позволяют делать все то, что хочется; 2) я не всегда вежлива, особенно с теми людьми, которые мне неприятны; 3) я не всегда готова признавать ошибку; 4) иногда я стараюсь получить реванш, вместо того чтобы простить обидчика (Bui, 2016: 216).

Исследования показали, что все подфакторы данной группы имеют существенное значение в качестве рисков женского противоправного поведения. Молодым женщинам, совершившим противоправные деяния, присуще субъективное ощущение одиночества, интровертированность. Как отмечает Л.М. Щербакова, «у женщин-преступниц проявляется повышенная личностная тревожность, а также неуверенность в себе, чрезмерное беспокойство. Они легко ранимы, впечатлительны и в значительной степени чувствительны к реакциям окружающих» (Щербакова, 2013: 38).

Второй фактор риска - влияние родителей/семьи - включает: асоциальное поведение родителей; насилие в семье; развод; психопатологию родителей; антиобщественное поведение в семье; структуру семьи; проживание в малообеспеченной, бедной семье; а также нарушение детско-родительских отношений и отсутствие контроля со стороны родителей.

Исследователи отмечают, что родители девушек, совершающих противоправные поступки, менее чувствительны к эмоциональным потребностям детей, испытывают больше трудностей в принятии своих родительских ролей, что, возможно, проявляется в непоследовательном и чрезмерно строгом воспитании (McCord, 2002: 20).

Значение родительского/семейного фактора риска находит отражение в «теории выживания» (girls survival theory), согласно которой вероятность девушек и женщин стать жертвами преступлений значительно выше, чем у мальчиков и мужчин, особенно если это преступления сексуального характера. Например, в США каждая четвертая девушка подвергается сексуальному насилию до достижения 18 лет (Laster, 2008: 38). По данным М. Чесней-Линд, опыт насилия, полученный мальчиками, оказывает на них глубокое и длительное травматическое действие, однако девочки чаще становятся непосредственными жертвами преступлений (Chesney-Lind, 2011: 143). Вырастая, те, кто испытал в детстве сексуальное насилие, имеют значительные искажения в психологическом развитии. Многочисленные исследования показывают, что наиболее распространенными последствиями перенесенного насилия является высокая вероятность совершения преступных деяний. Так, Д. Сайгел и Л. Вильямс пришли к выводу, что среди женщин, арестованных за насильственные преступления, многие являются бывшими жертвами сексуального насилия (Siegel, 2003: 71-94). Согласно результатам другого исследования, 50\% женщин-преступниц и лишь 12\% мужчин-преступников отметили, что они были жертвами насилия в прошлом (Weiler, 1999: 156).

Согласно «теории выживания» многие девушки совершают побеги из дома для того, чтобы избежать сексуального насилия, а на улице, оказавшись без надзора 
семьи, школ, социальных служб, они быстро вовлекаются в преступную деятельность, занимаются проституцией, совершают кражи, употребляют и сбывают наркотики (Ильченко, 2009: 288).

Важным подфактором группы является распад семьи. Риском выступает не сам факт развода родителей, а его прямые и косвенные последствия. Например, стресс, испытываемый родителем (обычно матерью), который после развода остается с ребенком, может обострить конфликты между ним и ребенком. Матери-одиночки при этом страдают от слабой социальной поддержки, испытывают финансовые затруднения, не имеют возможности отдохнуть от домашних обязанностей и потому после развода обычно мало занимаются воспитанием детей. Безусловно, это зависит от особенностей матери: так, Дж. Мак-Корд с коллегами установили, что вероятность совершения преступлений детьми, воспитываемыми в семьях без отца, снижалась в тех случаях, когда мать не имела склонности к противоправному поведению, а отношения между родителями и детьми оставались доверительными (McCord, 2002: 23). Дополнительные заботы и обязанности матери-одиночки сокращают возможности надзора за ребенком. Недостатком надзора можно объяснить вывод Л. Штейнберга о том, что так называемые «дети с ключом на шее», возвращающиеся из школы в пустой дом (поскольку мать еще работает), более чувствительны к давлению сверстников, убеждающих совершить антисоциальные поступки (Steinberg, 1986: 845).

Кроме того, распавшаяся семья является подфактором риска противоправного поведения, поскольку изменяются социальные взаимосвязи семьи, например, возникают стереотипные представления о детях разведенных родителей как о девиантах, что может стать самоисполняющимся пророчеством.

Еще одним подфактором риска является криминальное поведение родителей. В целом результаты многочисленных исследований показывают, что преступники гораздо чаще, чем непреступники, имеют криминальных родителей (McCord, 2002: 27). В свою очередь, бывшие правонарушители, став родителями, часто имеют делинквентных детей. Р. Блэкборн приводит несколько возможных объяснений. Согласно одному из них эта связь обусловлена генетическими факторами, общими у родителя и ребенка. Второе объяснение состоит в том, что родители служат моделями антисоциального поведения (Блэкборн, 2004: 126). Результаты исследований показали, что зависимость выражена сильнее, если родители совершают преступные действия в период несовершеннолетия ребенка, и не обнаруживается, в случае если родители впервые совершают преступление после достижения ребенком совершеннолетия (Wells, 1986: 68). Родительская криминальность коррелирует также с отсутствием постоянной работы и зависимостью от социальных пособий, что может вносить свой вклад в распад семьи. Дж. Мак-Корд установила, что родительская девиантность давала наибольший эффект, когда сочеталась с родительской агрессивностью и конфликтом в семье, но ее эффект был заметно слабее, если отец проявлял уважение к матери и любовь к ребенку (McCord, 2002: 28).

С точки зрения теории дифференциальной ассоциации Э. Сатерленда и Д. Кресси, девушки значительно реже контактируют с представителями преступ- 
ного мира, что препятствует им овладеть криминальными ценностями и нормами поведения (Sutherland, 1960). Однако влияние на уменьшение риска преступного поведения оказывает не биологический пол как таковой, а более жесткий социальный контроль над девочкой, осуществляемый ее семьей и другими социальными институтами.

Исследование, проведенное американскими учеными, также показало, что хорошие взаимоотношения с родителями препятствуют девиантному поведению. Согласно полученным данным, чем крепче связь между матерью и дочкой, тем выше уровень самоуважения девушек и тем ниже вовлеченность в делинквентное поведение (Smith-Adcock, 2005: 310).

Дж. Хаган и А. Гиллис, авторы теории контроля власти, считали, что всех членов общества можно разделить на две категории: тех, кто контролирует, и тех, кого контролируют (Hagan, 1982). Согласно этой теории осуществление семейного контроля зависит от экономической и властной позиции главы семьи. Если один из супругов имеет власть над людьми на своем рабочем месте, то он (или она) будет стремиться контролировать детей дома (особенно девочек). Но в то же время родители, обладающие властью на работе, более склонны оправдывать девиантное поведение своих детей, особенно сыновей. Так, наибольшей свободой и вольностью в совершении девиантных поступков обладают молодые люди из высшего класса, распространение девиантности среди которых объясняется не только свободой действий, предоставленной им родителями (особенно со стороны матерей), но убеждением о возможности избежать реального наказания за совершенные противоправные поступки.

Позже Д. Хаган, А. Гиллис и Д. Симпсон модифицировали свою теорию, сделав на акцент на изучении уровня контроля над детьми в патриархальных и эгалитарных семьях, а также в семьях, где позицию лидера занимает женщина. По мнению авторов, в эгалитарных семьях делинквентность девушек должна возрастать и приближаться по своему уровню к мужской. Они также предположили, что делинквентность возрастает в семьях, возглавляемых женщинами.

Критики считают, что теория контроля власти должна быть пересмотрена, в том смысле, что позиция, занимаемая матерью на работе, и распределение власти в семье мало соотносятся с делинквентным поведением детей (Chesney-Lind, 2011: 202).

Третий фактор риска - окружение сверстников - включает в себя как связь с подростками с асоциальным поведением, так и отторжение со стороны сверстников.

Многочисленными исследованиями было установлено, что одним из самых сильных подфакторов риска совершения преступлений молодежью является делинквентность близких друзей. Риск женской молодежной преступности многократно возрастает, если девушка взаимодействует со сверстниками с асоциальным поведением.

Самым сильным подфактором риска может быть влияние братьев и сестер, совершающих противоправные деяния. Криминологи Ш. Глюк и Э. Глюк отмечают, что 65\% их выборки имели брата или сестру (сиблинга), с которым совместно или по отдельности совершали преступления (Glueck, 1951). Эффект «пагубного 
влияния» отражает тенденцию молодежи больше полагаться на своих сиблингов, выступающих для них в качестве образца для подражания (Блэкборн, 2004: 138).

Другим подфактором риска является совместное, групповое совершение преступлений. В настоящее время примерно две трети молодежных преступлений совершаются не в одиночку, а преимущественно малыми группами, состоящими из двух-пяти человек. Совершение преступлений в соучастии с другими, включая родных братьев и сестер, наиболее характерно для юных преступников, причем соучастники обычно проживают рядом друг с другом и близко от места преступления (Farrington, 2007: 125).

Отверженность сверстниками - еще один серьезный подфактор риска преступности несовершеннолетних женского пола. Исследования Дж. Паттерсона, Д. Капалди показали, что отверженность сверстниками является предпосылкой асоциального поведения в последующем (Patterson, 1991). По мнению авторов, именно отвержение сверстниками агрессивных и неумелых в социальном плане подростков побуждает их присоединиться к сверстникам, находящимся в сходном положении, вынуждая отвергнутого ребенка к общению с девиантными сверстниками и бандами. Иными словами, агрессивные молодые женщины менее популярны среди сверстников, но они не всегда находятся в социальной изоляции, а склонны завязывать дружеские отношения с такими же агрессивными людьми (Романова, 2012: 144).

Отличительной особенностью такого фактора риска преступности несовершеннолетних женского пола, как «окружение сверстников», является его двусторонний процесс. Группы сверстников с асоциальным поведением выбираются индивидуумами, но в то же время они сами вырабатывают у своих членов противоправное поведение. Так, согласно результатам лонгитюдных исследований, наиболее высокие показатели делинквентности были у тех, кто имел слабые связи с родителями и нормально ведущими себя сверстниками и сильные связи с девиантными сверстниками. Эти результаты лучше всего согласуются с выводами теории социального научения, согласно которым мотивация к делинквентности не является неотъемлемой и неизменной, а зависит от того, какая группа предоставляет социальное подкрепление (Блэкборн, 2004: 140).

Завершая анализ данного фактора риска, следует отметить, что, как предполагают М. Готфредсон и Т. Хирши, группа сверстников может облегчить совершение преступлений, но криминальная склонность, вероятно, является сформированной уже к началу подросткового возраста (Gottfredson, 1990).

Четвертый фактор риска преступности несовершеннолетних женского пола - школьный - характеризуется неудачами, связанными с обучением в школе; низкими академическими показателями и интересами.

Исследования показывают, что молодые женщины, не заинтересованные в школьном обучении, или те, кто не в состоянии закончить образование, имеют больший риск совершения противоправных деяний (Bui, 2016: 211). Кроме того, у несовершеннолетних правонарушителей стремление к получению высшего образования гораздо менее выражено, чем у остальной молодежи. Отвечая на вопрос об 
академических способностях, большинство подростков с противоправным поведением ответили, что они учатся хуже всех в классе (McCord, 2002: 22).

Хотя исследования взаимосвязи процесса обучения и преступности несовершеннолетних женского пола противоречивы, они все-таки связаны с асоциальным поведением учащихся. В качестве подфакторов риска могут выступать: низкий уровень удовлетворенности учителей; слабое взаимодействие между учителями; плохие отношения между учителями и школьниками; превалирование норм и ценностей, поддерживающих асоциальное поведение; неопределенные или противоречивые правила ожидаемого поведения; неадекватный контроль над исполнением правил (Романова, 2012: 145). Следует особо отметить, что указанные подфакторы имеют особое значение в самом начале девиантной карьеры (Шипунова, 2015).

Взрослые преступницы часто имеют лишь базовый уровень образования (Ильченко, 2012: 69). Однако роль школы как фактора риска женской молодежной преступности остается неясной. Некоторые исследователи полагают, что система образования способствует возникновению делинквентности, навязывая стандарты среднего класса молодежи из рабочего класса, которая не желает их принимать. «Радикальные криминологи идут еще дальше, утверждая, что всеобщее обязательное обучение было задумано для формирования у большинства повиновения и готовности выполнять повседневные рутинные задания на производстве: те, кто мешает этому и становится делинквентом, просто восстают против требования заниматься отчужденным трудом» (Блэкборн, 2004: 139).

Синтезируя результаты исследований о влиянии школы на формирование противоправного поведения, ученые пришли к мнению: «типичная» школа с высоким уровнем делинквентности учащихся расположена в относительно неблагоприятном районе; преподаватели убеждены в невысоких способностях учащихся, вследствие чего не стремятся к получению высоких академических результатов; присутствует постоянная текучесть кадров, препятствующая установлению доверительных отношений между персоналом школы и учащимися (Блэкборн, 2004: 141).

Пятый - фактор сообщества - включает знание своих соседей и общение с ними. Влияние сообщества является одним из факторов риска или, напротив, превенции противоправного поведения. В опроснике Л. Бай данный фактор характеризуется всего одним утверждением: я не знаю, кто мои соседи, или знаю немногих (Bui, 2016: 216). Отрицательный ответ на данный вопрос позволяет исследователям сделать вывод о том, что неофициальный социальный контроль, осуществляемый путем реализации правил, установленных социальными группами, выступает эффективной мерой предотвращения преступлений. Мнение социальной группы, членом которой является человек, может удерживать его от совершения преступления. Нам представляется, что мнение сообщества имеет большее значение для девушек, чем для молодых людей.

Влияние сообщества как фактора риска преступности несовершеннолетних женского пола хорошо иллюстрирует теория Р. Мертона, согласно которой преступление совершается в случае, если существует разрыв между ценностями, принятыми в обществе (например, успех, богатство, статус), и законными средствами до- 
стижения этих целей. Члены сообщества могут иметь традиционные представления о месте и роле женщины в обществе либо, напротив, поддерживать идеи о дискриминации женщин и гендерном неравенстве. В таком сообществе молодые женщины стремятся к тем же социально одобряемым целям, что и мужчины (хорошо оплачиваемая работа, образование, успешная карьера), но, возможно, имеют меньше шансов для их достижения. Разрыв между целями и средствами их достижения может способствовать росту женской молодежной преступности.

Традиционно женщины обладают весьма небольшим набором доступных средств достижения таких инструментальных целей, как богатство или успех в обществе. На протяжении вековой истории статус, материальное и социальное положение женщины приобретались благодаря замужеству или передавались от родителей. В настоящее время девочкам из неблагоприятной социальной среды по-прежнему сложно достигать ценностей, принятых в обществе, что в конечном счете способствует формированию девиантности. В этом смысле, как пишет Н. Бартон, преступное поведение женщин является дважды девиантным: во-первых, из-за выбора незаконных средств достижения цели, а во-вторых, изза резкого отклонения от социально одобряемых образцов поведения женщины (Barton, 1965: 20).

В данном контексте представляют интерес исследования, проведенные Д. Гипсер, которые основываются на положении Мертона о соответствии/несоответствии целей способам их достижения. На основе изучения самооценки молодых преступниц исследовательница попыталась ответить на вопрос о взаимосвязи поведения девушек с их социальными проблемами (Gipser, 1987: 86). По мнению автора, делинквентное поведение возникает в случае ролевой путаницы (неопределенности или недостижимости цели в рамках определенной роли), а также в случае легкодоступности (в некоторых сообществах) незаконных средств достижения цели.

Итак, мы рассмотрели основные факторы риска молодежной преступности, к которым отнесли индивидуальный, родительский/семейный, взаимодействие со сверстниками, влияние школы и сообщества.

\section{БИБЛИОГРАФИЧЕСКИЙ СПИСОК}

Акулич М.М., Комбарова Е.В. Социологическое изучение социальных рисков: история и современность. Вестник Тюменского государственного университета, 2008, No. 4, 55-62.

Блэкборн Р. Психология криминального поведения. СПб.: Питер, 2004.

Ильченко О.Ю., Хорошилова А.А. Криминологическая характеристика женской преступности. Криминология: вчера, сегодня, завтра, 2012, No. 26, 67-70.

Ильченко О.Ю. Беспризорность несовершеннолетних как результат насилия в семье. Известия Российского государственного педагогического университета им. А.И. Герцена, 2009, №. 99, 286-290. 
Романова Е.Н. Делинквентность детей раннего возраста и меры воздействия на ее проявление в исследованиях зарубежных ученых. Вестник Бурятского государственного университета, 2012, No. 5, 143-148.

Тейван-Трейновский Я., Нестерова М.М., Лавриненко О.Я. Анализ факторов риска преступности несовершеннолетних в Латвии. Криминологический журнал Байкальского государственного университета экономики и права, 2013, No. 2, 102-110.

Шипунова Т.В. Социальный контроль девиантности и его дискурсивное конструирование. Вестник Санкт-Петербургского университета, Серия 12: Психология. Социология. Педагогика, 2015, No. 3, 102-109.

Щербакова Л.М., Белая О.П. Индивидуально-психологический профиль женщин, осужденных за насильственные преступления. Криминологический журнал Байкальского государственного университета экономики и права, 2013, No. 4, 35-44.

Andrews D.A., Bonta J. The Psychology of Criminal Conduct. New York: Routledge, 2014.

Barton N.J. Disregarded Delinquency: a Study of Self-Reported middle class female Delinquency in a suburb. Ann Arbor: Michigan, 1965.

Bui L., Farrington D.P., Ueda M. Potential risk and promotive factors for serious delinquency in Japanese female youth. International journal of comparative and applied criminal justice, 2016, No. 3, 209-224.

Chesney-Lind M., Morash M. Feminist theories of crime. Burlington: Ashgate publishing, 2011.

Farrington D.P. Explaining and preventing crime: The globalization of knowledge - The American society of criminology 1999 presidential address. Criminology, 2000, No. 38, $1-24$.

Farrington D.P. Gender differences in offending: Implications for risk-focused prevention. London: Home Office, 2004.

Farrington D.P., Welsh B.C. Saving children from a life of crime. New York: Oxford University Press, 2007.

Gipser D. Frauen und Kriminalität. Weinheim: Beltz, 1987.

Glueck S., Glueck. E. Unravelling Juvenile Delinquency. London: Oxford University Press, 1951.

Gottfredson M.R., Hirschi T. A General Theory of Crime. Stanford: Stanford University Press, 1990.

Hagan J., Gillis A. Density, delinquency and design formal and informal control and the built environment. Criminology, 1982, No. 19, 514-529.

Hawkins J.D., Catalano R.F., Miller J.Y. Risk and protective factors for alcohol and other drug problems in adolescence and early adulthood: Implications for substance abuse prevention. Psychological Bulletin, 1992, No 112, 64-105.

Laster L. Dwayne Abuse, trauma, and social bonding in the etiology of female delinquency. Arlington: Univ. of Texas, Diss., 2008. 
McCord J., Conway K.P. Patterns of juvenile delinquency and co-offending. Advances in Criminological Theory, 2002, No. 10, 15-30.

Patterson G.R., Capaldi D.M. Bank L. An early starter model for predicting. Hillsdale: Lawrence Erlbaum, 1991. Pp. 139-168.

Siegel J.A., Williams L.M. The relationship between child sexual abuse and female delinquency and crime: A prospective study. Journal of research in Crime and Delinquency, 2003, No. 40, 71-94.

Smith-Adcock S., Kerpelman J. Girls self-perception of reputation and delinquent involvement. International Journal of Adolescence and Youth, 2005, No. 12, 301-323.

Steinberg L., Silverberg S.B. The Vicissitudes of Autonomy in Early Adolescence. Child Development, 1986, No. 4, 841-851.

Sutherland E.H., Cressey D.R. Principles of Criminology. Chicago: Lippincott, 1960.

Weiler P., Mizunami A. Gerechtigkeit in der sozialen Ordnung: Die Tugend der Gerechtigkeit im Zeitalter der Globalisierung (Beiträge zur politischen Wissenschaft). Berlin: Duncker \& Humblot, 1999.

Wells L.E., Rankin J. The broken homes model of delinquency: Analytic issues. Journal of Research in Crime and Delinquency,1986, No. 23, 68-93.

\section{REFERENCE}

Akulich, M.M, Kombarova, E.V. (2008). Sociologicheskoe izuchenie socialnich riskov: istoria i sovremennost [Sociological study of social risks: history and contemporaneity], Vestnik Tyumenskogo gosudarstvennogo universiteta [Bulletin of Tyumen State University], no 4, 55-62.

Blackborn, P. (2004). Psihologiya kriminal'nogo povedeniya [Criminal Behavior: A Psychosocial Approach]. SPb.: Piter.

Ilchenko, O.Yu., Khoroshilova, A.A. (2012). Kriminologicheskaya harakteristika zhenskoj prestupnosti [Criminological characteristics of female crime]. Criminology: yesterday, today, tomorrow, no 26, 67-70.

Ilchenko, O.Yu. (2009) Besprizornost nesovershennoletnix kak rezultat nasilia v semye [Child neglect as a result of domestic violence]. Izvestia: Herzen University Journal of Humanities a Science [News of the Russian State Pedagogical University. A.I. Herzen], no 99, 286-290.

Romanova, E.N. (2012). Delinkventnost detez rannengo vosrasta i mery vozdeystvia na eyo proyavlenie $\mathrm{v}$ issledovanyach zarubezhnyx ychenyzh [Delinquency of young children and measures to influence its manifestation in the studies of foreign scientists]. Vestnik Buryatskogo gosudarstvennogo yniversiteta [Bulletin of the Buryat State University], no 5, 143-148.

Taiwan-Treinovskis, J., Nesterova, M.M., Lavrinenko, O.Ya. (2013) Analiz faktorov riska prestupnosti nesovershennoletnih $\mathrm{v}$ Latvii [Analysis of risk factors of juvenile crime in Latvia]. Kriminologicheskij zhurnal Bajkal'skogo gosudarstvennogo universiteta ekonomiki i prava [The Criminological magazine of the Baikal state University of Economics and law], no 2, 102-110. 
Shipunova, T.V. (2015) Social'nyj kontrol' deviantnosti i ego diskursivnoe konstruirovanie [Social control of deviance and its discursive construction]. Vestnik Sankt-Peterburgskogo universiteta, Seriya 12: Psihologiya. Sociologiya. Pedagogika [Bulletin of St. Petersburg University. Episode 12. Psychology. Sociology. Pedagogy], no 3, 102-109.

Shcherbakova, L.M., Belaya, O.P. (2013). Individual'no-psihologicheskij profil' zhenshchin, osuzhdennyh za nasil'stvennye prestupleniya [Individual psychological profile of women convicted of violent crimes]. Kriminologicheskij zhurnal Bajkal skogo gosudarstvennogo universiteta ekonomiki i prava [Criminological journal of the Baikal state University of Economics and law], no 4, 35-44.

Andrews, D.A., Bonta, J. (2014). The Psychology of Criminal Conduct. New York: Routledge.

Barton, N.J. (1965). Disregarded Delinquency: a Study of Self-Reported middle class female Delinquency in a suburb. Ann Arbor: Michigan.

Bui, L., Farrington, D.P., Ueda, M. (2016). Potential risk and promotive factors for serious delinquency in Japanese female youth. International journal of comparative and applied criminal justice, no 3, 209-224.

Chesney-Lind, M., Morash, M. (2011). Feminist theories of crime. Burlington: Ashgate publishing.

Farrington, D.P. (2000). Explaining and preventing crime: The globalization of knowledge - The American society of criminology 1999 presidential address. Criminology, no $38,1-24$.

Farrington, D.P. (2004). Gender differences in offending: Implications for risk-focused prevention. London: Home Office,.

Farrington, D.P., Welsh, B.C. (2007). Saving children from a life of crime. New York: Oxford University Press,.

Gipser, D. (1987). Frauen und Kriminalität. Weinheim: Beltz.

Glueck, S., Glueck, E. (1951). Unravelling Juvenile Delinquency. London: Oxford University Press.

Gottfredson, M.R., Hirschi, T. (1990). A General Theory of Crime. Stanford: Stanford University Press.

Hagan, J., Gillis, A. (1982). Density, delinquency and design formal and informal control and the built environment. Criminology, no 19, 514-529.

Hawkins, J.D., Catalano, R.F., Miller J.Y. (1992). Risk and protective factors for alcohol and other drug problems in adolescence and early adulthood: Implications for substance abuse prevention. Psychological Bulletin, no 112, 64-105.

Laster, L. (2008). Dwayne Abuse, trauma, and social bonding in the etiology of female delinquency. Arlington: Univ. of Texas, Diss.

McCord, J., Conway, K.P. (2002). Patterns of juvenile delinquency and co-offending. Advances in Criminological Theory, no 10, 15-30.

Patterson, G.R., Capaldi, D.M. Bank, L. (1991). An early starter model for predicting (pp. 139-168). Hillsdale: Lawrence Erlbaum. 
Siegel, J.A., Williams, L.M. (2003). The relationship between child sexual abuse and female delinquency and crime: A prospective study. Journal of research in Crime and Delinquency, no 40, 71-94.

Smith-Adcock, S., Kerpelman, J. (2005). Girls self-perception of reputation and delinquent involvement. International Journal of Adolescence and Youth, no 12, 301-323.

Steinberg L., Silverberg, S.B. (1986). The Vicissitudes of Autonomy in Early Adolescence. Child Development, no 4, 841-851.

Sutherland, E.H., Cressey, D.R. (1960). Principles of Criminology. Chicago: Lippincott,. Weiler, P., Mizunami, A. (1999). Gerechtigkeit in der sozialen Ordnung: Die Tugend der Gerechtigkeit im Zeitalter der Globalisierung (Beiträge zur politischen Wissenschaft). Berlin: Duncker \& Humblot.

Wells, L.E., Rankin, J. (1986). The broken homes model of delinquency: Analytic issues. Journal of Research in Crime and Delinquency, no 23, 68-93. 